\title{
Sifat Fisika Material Pembentuk OLED: Sebuah Telaah Ilmiah
}

\author{
Lukas B. Setyawan \\ Program Studi Teknik Elektro, \\ Fakultas Teknik Elektronika dan Komputer, \\ Universitas Kristen Satya Wacana, Salatiga \\ lukas.setyawan@staff.uksw.edu
}

\begin{abstract}
Ringkasan
Perkembangan teknologi OLED untuk bidang penampilan dan perlampuan sangat menjanjikan. Hal ini diperkuat karena ongkos fabrikasi perangkat optoelektroniika menggunakan material organik lebih murah dibandingkan dengan perangkat menggunakan material non-organik. Telaah ini membahas lebih dahulu konfigurasi OLED tipe small molecular (SMOLED) dan tipe polymer (PLED). Berikutnya dibahas material pembentuk OLED dan sifat fisikanya. Material organik yang digunakan berbeda satu dengan yang lain bukan hanya karena strukturnya tetapi juga mekanisme yang terjadi pada proses electroluminescence (fluorescence atau phosphorescence). Bila material organik ditumpuk secara benar akan diperoleh perangkat OLED yang memiliki efisiensi tinggi dan umur-kerja lebih lama. Tiga proses yang sangat penting untuk menentukan efektifitas OLED adalah injeksi muatan, pengangkutan muatan, dan emisi cahaya. Berbagai lapisan pada tumpukan material organik dimaksudkan untuk memenuhi tiga proses tersebut, seperti modifikasi pada permukaan Hole Injection Layer (HIL) dan Electron Injection Layer (EIL), pemilihan material yang memiliki mobilitas tinggi untuk pengangkutan seperti Hole Transport Layer (HTL) dan Electron Transport Layer (ETL), demikian juga lapisan emisi dengan pengedop emitter yang memiliki efisiensi tinggi. Warna cahaya yang terbentuk ditentukan oleh pita celah (band gap) material semikonduktor. Digunakan lapisan EML yang berbeda untuk menghasilkan warna yang berbeda.
\end{abstract}

Kata kunci: organic light-emitting diode, polymer light-emitting diode, electroluminescence, fluorescene, phosphorescence

\section{Pendahuluan}

OLED (Organic Light-Emitting Diode) adalah Light-Emitting Diode (LED) dimana lapisan emissive electroluminescent merupakan lembaran senyawa organik yang akan memancarkan cahaya bila dilalui arus elektrik. Lapisan bahan semikonduktor organik ini diletakkan di antara dua elektroda. Umumnya salah satu elektroda tersebut tembus pandang. Konfigurasi dasar OLED memiliki susunan seperti Gambar 1.

OLED memiliki ketebalan sebesar 100 sampai 500nanometer, sekitar 1/200 ketebalan rambut manusia. Lapisan bahan organik untuk menyusun OLED bisa 2 atau 3 lapis. Struktur dasar OLED terdiri dari bahan organik yang diletakkan di antara katode dan anode, yang terbuat dari indium tin oxide (ITO) tembus pandang. Sedangkan bahan organik tersusun beberapa lapis lembaran tipis, meliputi Hole Transporting Layer (HTL), Emissive Layer (EML), dan Electron Transporting Layer (ETL). Dengan memberikan 
tegangan yang sesuai, hole dari anode akan masuk ke EML dan elektron dari katode akan masuk ke EML. Di dalam EML hole dan elektron bergabung sehingga terjadi electroluminescene. Bahan HTL, ETL, EML, dan pilihan elektrode merupakan faktor kunci yang menentukan kualitas OLED.

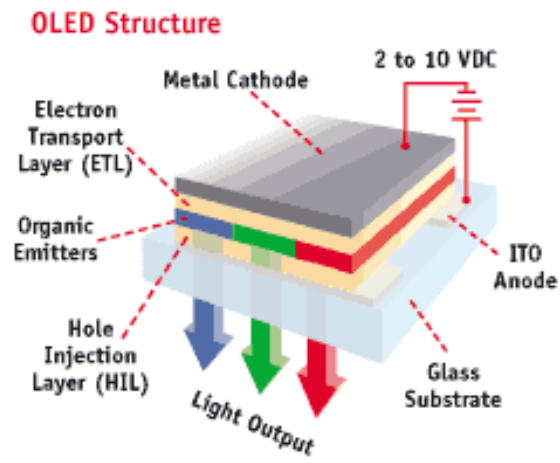

Gambar 1. Konfigurasi OLED [1]

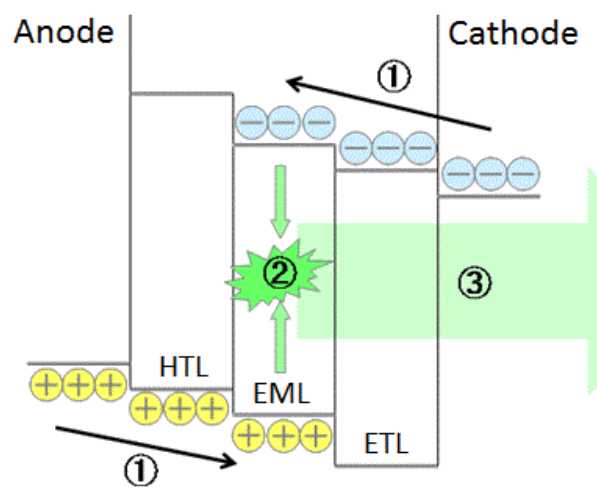

Gambar 2. Skema mekanisme electroluminescence pada OLED [2][3]. (1) Elektron (biru) dan hole (kuning) disuntikkan dari elektroda menuju lapisan emisif organik (EML). (2) terbentuk pasangan elektron-hole atau exciton (hijau). (3) rekombinasi exciton akan menyebabkan terjadinya emisi foton.

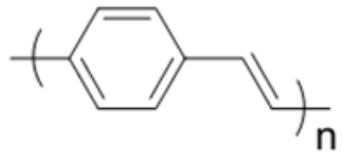

a

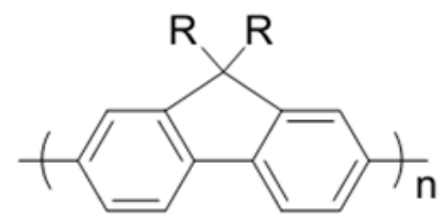

b

Gambar 3. Polymer yang paling banyak digunakan untuk menghasilkan electroluminescence pada OLED [2][3]. (a) Poly-para-phenylene vinylene (PPV) (b) Polyfluorenes (PFO)
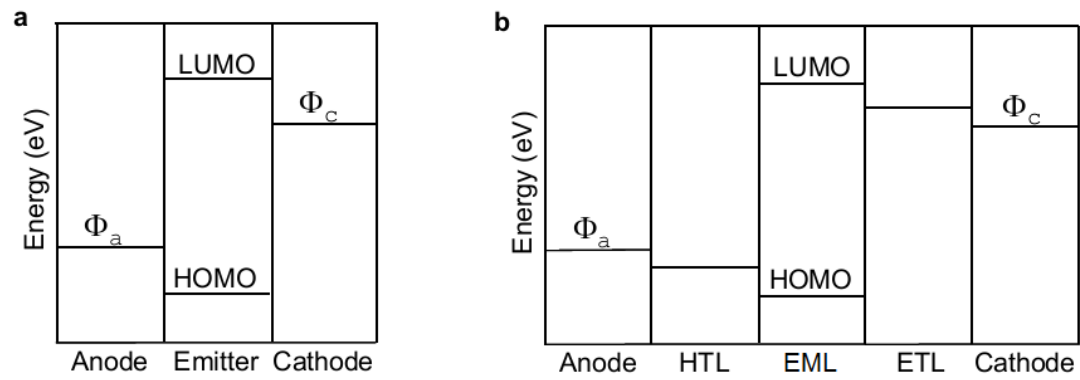

Gambar 4. Diagram energi level [3]. (a) OLED lapis tunggal (b) OLED lapis jamak dengan hole transporting layer (HTL) dan electron transporting layer (ETL) disisipi emissive layer (EML). 
Devais OLED dibedakan menjadi dua macam, tergantung dari tipe lapisan organiknya, yaitu:

1. Devais small molecule (SMOLED)

2. Devais organic polymer (PLED atau LEP).

Devais small molecule difabrikasi menggunakan teknik evaporasi vakum, dengan meletakkan struktur polymer secara spin-casting atau memakai teknik cetak ink-jet. Sebutan OLED biasanya mengacu ke small-molecular OLED.

Bagian-bagian penyusun OLED adalah sebagai berikut.

1. Substrat (plastik bening, kaca, foil)

Substrat digunakan sebagai tumpuan OLED. Sebagai substrat digunakan plastik, foil, atau kaca.

2. Anode (tembus pandang)

Anode biasanya menggunakan indium tin oxide (ITO). Material ini tembus pandang sehingga cahaya bisa terlihat dan cukup menghantar serta memiliki work function besar sehingga menjamin injeksi hole mencapai level HOMO dari lapisan organik. Biasanya lapisan konduktif yang memiliki sifat elektrode tembus pandang yang dipakai untuk menggantikan ITO terdiri dari polimer poly $(3,4-$ ethylenedioxythiophene) poly(styrenesulfonate) atau PEDOT:PSS karena memiliki level HOMO berada di antara work function ITO dan HOMO polimer lain yang biasa digunakan sehingga mengurangi rintangan energi (energy barrier) saat terjadi injeksi hole.

3. Electrons transport layer (ETL)

Komponen yang sering digunakan adalah: PBD, Alq3, TPBI, dan BCP (Gambar 5).
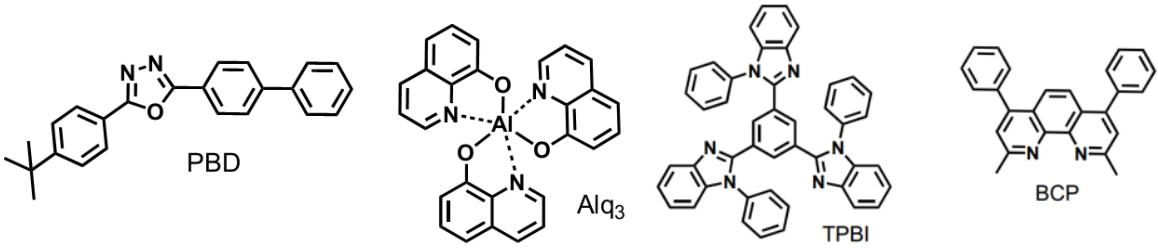

Gambar 5. Komponen yang sering digunakan pada electrons transport layer [3]. PBD = 2-(4-biphenyl)-5-(4-tbutylphenyl)-1,3,4-oxadiazole; Alq3= tris(8-hydroxyquinoline) aluminum; TPBI =1,3,5-tris(Nphenylbenzimidizol-2-yl)benzene; $\mathrm{BCP}=$ bathocuprene

4. Holes transport layer (HTL)

Material tipe-p yang sering digunakan sebagai HTL adalah: TPD dan NPB (Gambar 6).
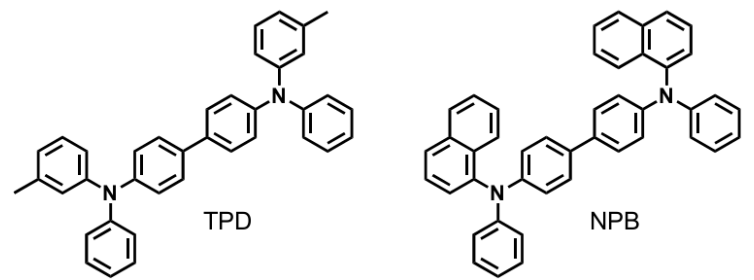

Gambar 6. Komponen yang sering digunakan pada holes transport layer [3]. TPD =N,N-diphenyl-N,N-bis(3methylphenyl)-1,1-biphenyl-4,4-diamine; NPB = 1,4-bis(1-naphthylphenylamino)biphenyl

5. Lapisan emisif

Lapisan ini terbuat dari molekul plastik organik (berbeda dengan di lapisan konduktif) yang berfungsi untuk mengangkut elektron dari katode. Di lapisan ini 
cahaya dihasilkan. Salah satu polymer yang digunakan pada lapisan emisif adalah polyfluorene. Emiter tersebut adalah pewarna flurosens dan pewarna fosforesens. Pada semikonduktor organik hole secara umum lebih aktif bergerak dibanding elektron. Peluruhan keadaan tereksitasi mengakibatkan pemulihan level energi elektron, disertai dengan pancaran yang menyebar dengan frekuensi berada pada daerah visibel. Frekuensi radiasi ini tergantung pada celah pita (band gap) material, dalam hal ini adalah perbedaan energi antara HOMO dan LUMO. Warna dari cahaya yang dihasilkan berbeda-beda sesuai dengan tipe molekul organik yang digunakan. Untuk memperoleh tampilan berwarna digunakan beberapa lapisan organik. Faktor lain dari cahaya yang dihasilkan adalah intensitasnya. Makin besar arus yang diberikan ke OLED makin terang cahaya yang terjadi.

6. Katode (tembus pandang atau tidak tergantung pada jenis OLED)

Komponen katode yang dibutuhkan tergantung pada jenis OLED. Bahkan katode tembus pandang pun bisa digunakan. Biasanya digunakan metal seperti barium, kalsium, dan alumunium sebagai katode karena memiliki work function lebih kecil dibanding anode sehingga membantu proses injeksi elektron menuju level LUMO dari lapisan berbeda.

\section{Small-Molecular OLED}

Struktur diode p-n merupakan faktor penting untuk devais OLED. Struktur dasar SMOLED terdiri atas dua lapis lembaran tipis bahan organik, yaitu hole transport layerHTL (lapisan-p pada LED) dan electron transport layer - ETL (lapisan-n pada LED) yang disisipkan di antara anode dan katode (lihat Gambar 7). Kedua lapisan organik ini, masing-masing memiliki ketebalan sekitar $500 \AA$, merupakan media untuk mengangkut pembawa muatan menuju penghubung yang terbentuk di antara dua lapisan itu.

Salah satu struktur SMOLED paling dasar menggunakan bahan organik NPB (turunan dari naphthyl substituted benzidine) sebagai HTL dan Alq3 sebagai ETL. Pada struktur tipikal ini digunakan indium tin oxide (ITO) sebagai anode yang tembus pandang dan magnesium-doped silver (Mg:Ag) sebagai katode.

Pada saat diberikan tegangan, terjadi injeksi muatan elektron melalui katode dan hole melalui anode. Elektron akan diangkut menuju LUMO (Lowest Unoccupied Molecular Orbital) dari ETL, dan hole menuju HOMO (Highest Occupied Molecular Orbital) dari HTL. Melintasi rintangan kedua muatan akan melakukan rekombinasi dengan sebagian besar hole bergerak menuju Alq3 (Lihat Gambar 8). Exciton terbentuk pada Alq3 dan memancarkan cahaya fluroscence warna hijau.

Rekombinasi yang terjadi pada elektron dan hole menyebabkan pembentukan foton dengan frekuensi sesuai dengan celah energi $(E=h v)$ antara level LUMO dan level HOMO dari emitting molecule. Dengan demikian, daya elektrik yang diberikan pada elektrode diubah menjadi cahaya. Menggunakan material dan dopan yang berbeda dapat dibangkitkan warna yang berbeda dan dengan menggabungkan beberapa material akan diperoleh sumber cahaya warna putih. 


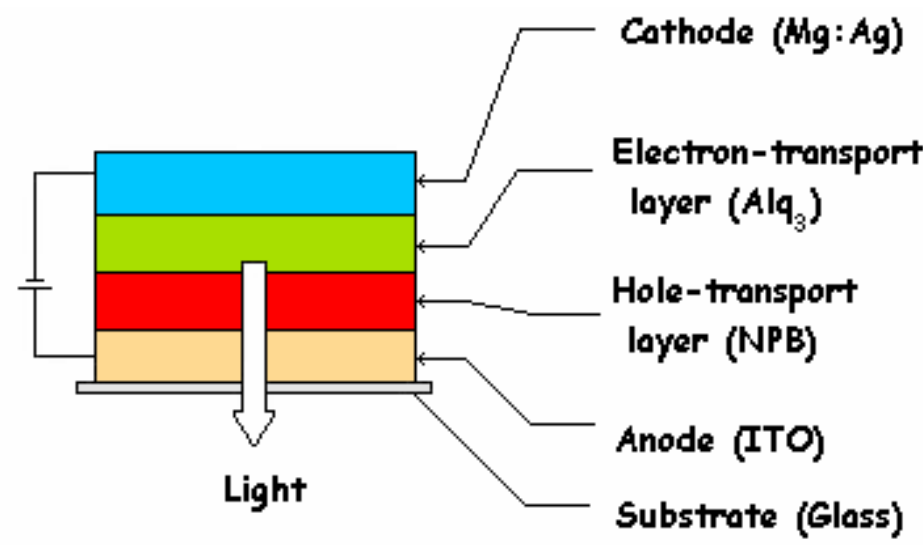

Gambar 7. Struktur dasar OLED terdiri atas lapisan hole-transport layer dan lapisan electron transport yang disisipkan di antara katode dan anode. [4]

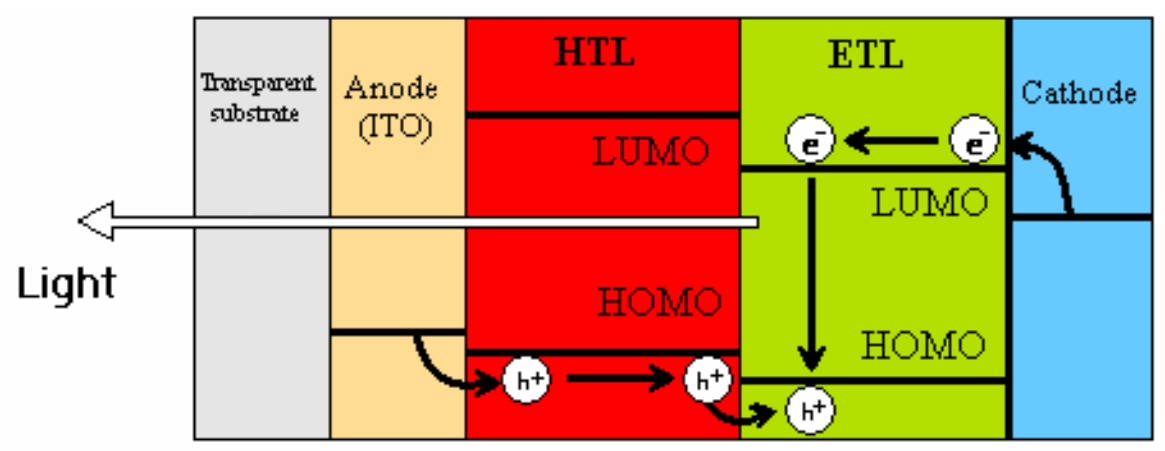

Gambar 8. Diagram energi pada SMOLED. [4]

Light Emitting Molecules

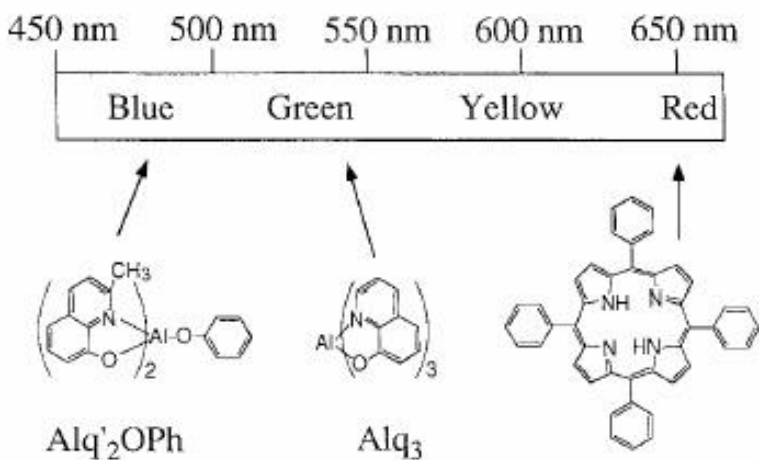

TPP

Hole Transporting Molecules

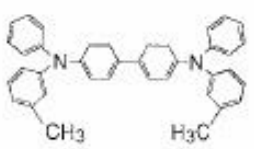

TPD

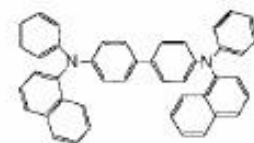

$\alpha-\mathrm{NPD}$

Gambar 9. Material yang digunakan pada OLED. 
Optimasi pada small molecule OLED dilakukan dengan memberikan dope phosphorescent kompleks $\operatorname{Ir}($ ppy)3 terhadap CBP. HTL adalah lapisan 4,4'-bis[N-(1naphthyl)-N-phenyl-amino]biphenyl (a-NPD). Molekul Bathocuprene (BCP) yang memiliki jarak HOMO-LUMO besar digunakan sebagai carrier dan exciton blocking layer. Katode bilayer terdiri atas lapisan tipis $(<10 \AA)$ LiF dan lapisan Al yang lebih tebal, digunakan untuk membuat injeksi elektron secara efisien.

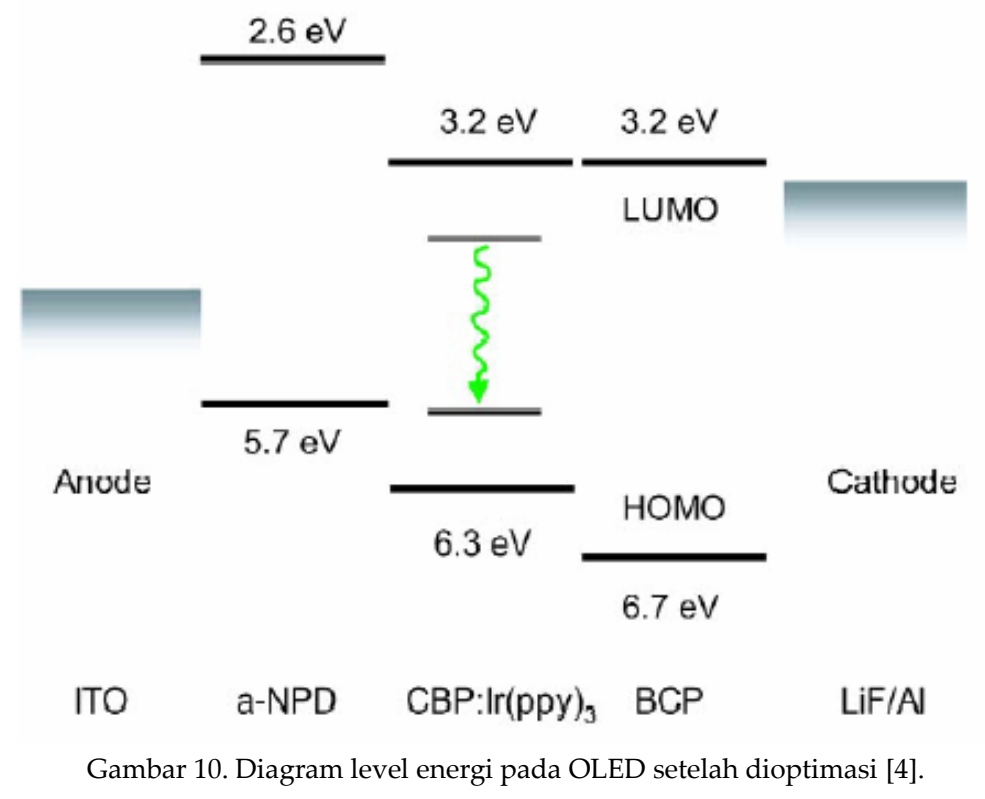

\section{PLED}

PLED tersusun atas satu atau lebih lapisan tipis semipenghantar organik yang disisipkan di antara dua elektroda, salah satu elektroda harus tembus pandang (transparan). (Gambar 11). Diagram level energi untuk PLED lapis tunggal diperlihatkan oleh Gambar 12. PLED ini menggunakan PPV (poly-para-phenylene vinylene) dengan ketebalan sekitar 100nm dan ITO sebagai anode serta kalsium sebagai katode.

Saat diberikan pra-tegangan maju maka elektron diinjeksikan dari katode menuju LUMO polymer dan hole diinjeksikan dari anode menuju HOMO polymer. Elektron harus mampu mengatasi rintangan (electron injection barrier) yang ada di antara level Fermi dari kalsium dan level LUMO dari polymer. Untuk memperkecil rintangan biasanya digunakan logam yang memiliki work function rendah seperti $\mathrm{Mg}$ atau $\mathrm{Ca}$ agar didapat kontak ohmic. Bila terdapat kesesuaian energi antara katode dan LUMO berarti tidak banyak energi yang terbuang ketika elektron diinjeksikan. Demikian juga, untuk menjamin agar terjadi kontak ohmic saat hole diinjeksikan dari level Fermi ITO menuju HOMO polymer, maka ITO perlu diberi perlakuan dengan berbagai cara (misalnya dilakukan pembukaan untuk dibersihkan menggunakan ultraviolet-ozone) agar level Ferminya lebih rendah. Rintangan di sini disebut hole injection barrier. 


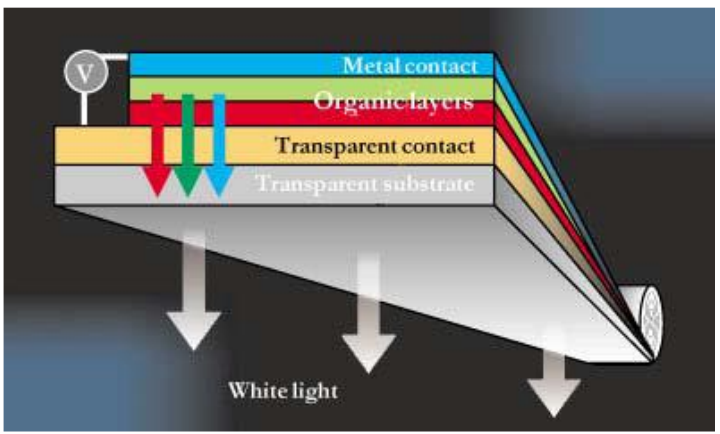

Gambar 11. Struktur dasar PLED (dua lapis) [4].

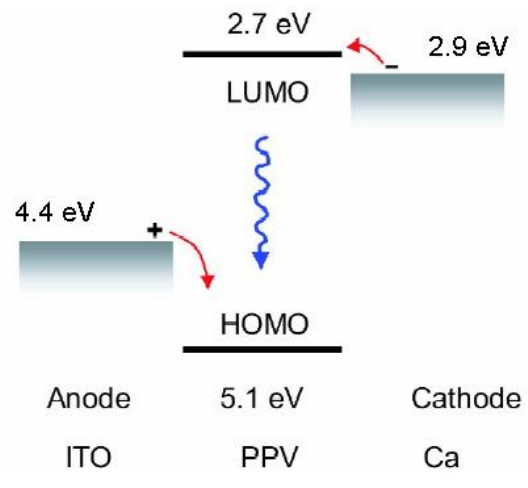

a)

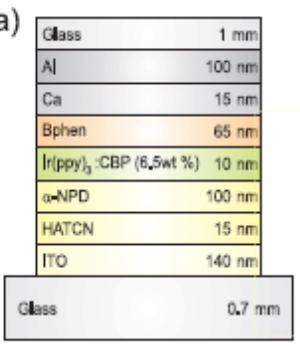

Gambar 12. Diagram energi PLED [4].

b)

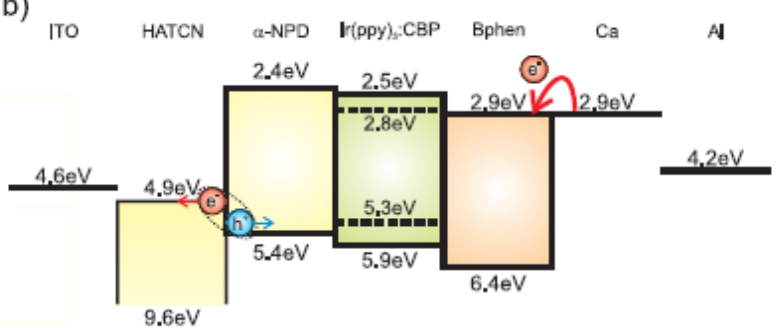

c)
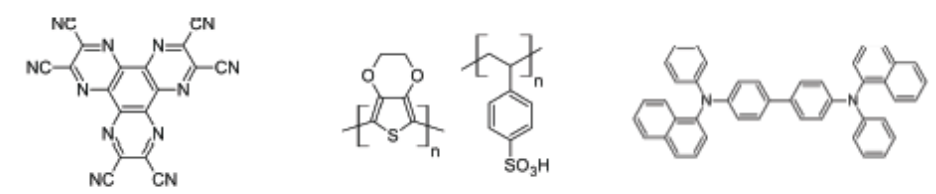

HATCN

PEDOT PSS

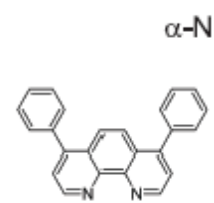

Bphen

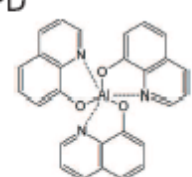

$\mathrm{Alq}_{3}$

$$
\text { TPD }
$$

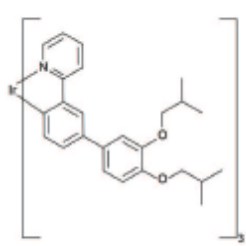

$\mathrm{Ir}=\mathrm{SC} 4$
CBP

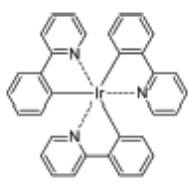

$\operatorname{Ir}(\mathrm{ppy})_{3}$

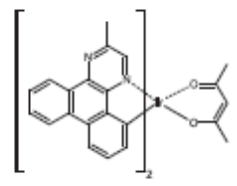

$\operatorname{Ir}(\mathrm{MDQ})_{2}(\mathrm{acac})$

Gambar 13. (a) Susunan OLED modern. (b) Diagram energi level HOMO dan LUMO molekul organik yang digunakan. (c) Struktur molekular material organik yang digunakan. [5] 
Gambar 13(a) memperlihatkan tata letak susunan OLED multilayer terdiri atas beberapa lapisan organik berbeda agar diperoleh kinerja OLED yang lebih baik daripada OLED satu lapis. Empat lapisan organik berbeda diletakkan pada indium tin oxide (ITO) yang memiliki ketebalan 140nm dan ditutupi dengan substrat dari kaca, yang telah dicuci sebelumnya dengan beberapa solvent (acetone, isopropanol) dalam bak ultrasonik dan disinari oleh UV-ozone dalam ruang khusus (cleanroom). Penyinaran dengan UVozone ini bukan sekedar proses pencucian saja tetapi sekaligus juga mengaktifkan permukaan ITO untuk menaikkan fungsi kerja (work function) ITO sehingga membantu proses injeksi hole ke dalam lapisan organik.

Lapisan pertama setebal $15 \mathrm{~nm}$ adalah hexa-azatriphenylene-hexanitrile (HATCN) sebagai lapisan penghasil hole, berikutnya lapisan $\alpha$-NPD setebal $100 \mathrm{~nm}$ bertindak sebagai hole transport layer (HTL) dievaporasi pada ITO yang menutupi substrate kaca. Lapisan berikutnya adalah senyawa dua molekul organik yang berbeda dan membentuk emission layer (EML), yaitu 4,4'-bis[9-carbazolyl]-2,2'-biphenyl (CBP) yang didope dengan 6,5wt $\%$ tris[2-phenylpyridine]iridium $(\operatorname{Ir}(\mathrm{ppy}) 3)$. Setelah EML adalah electron transport layer (ETL) yaitu Bphen dengan ketebalan 65nm. Terakhir, dideposit kalsium dengan ketebalan 15nm sebagai katode, dilindungi oleh lapisan aluminium setebal 100nm. Untuk melindungi lapisan organik dan katode terhadap pengaruh embun dan udara sekitar maka seluruh devais dienkapsulasi dengan selubung nitrogen oleh substrate kaca kedua yang dihubungkan dengan substrate dasar melalui perekat epoxy.

Gambar 14 menunjukkan tata letak susunan OLED dengan pancaran cahaya berbeda warna.

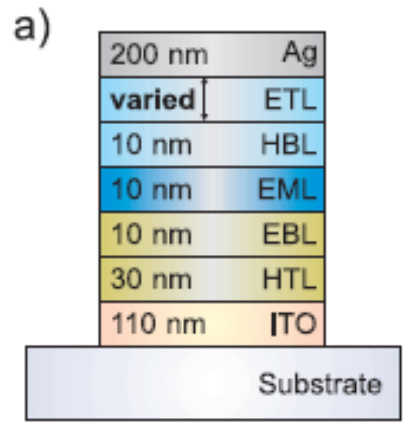

c)

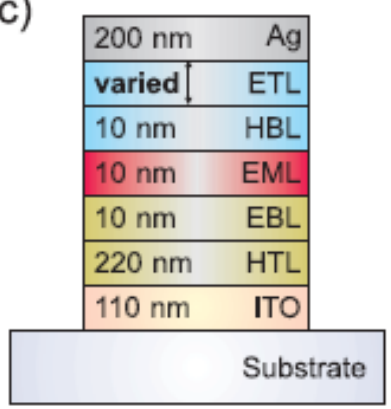

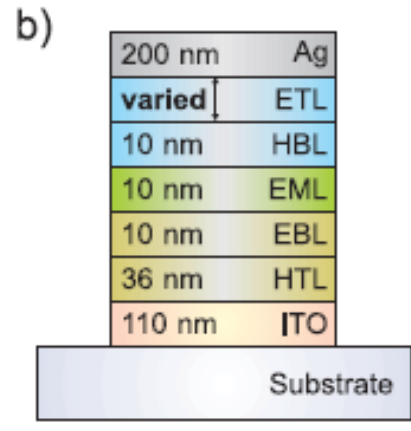

d)

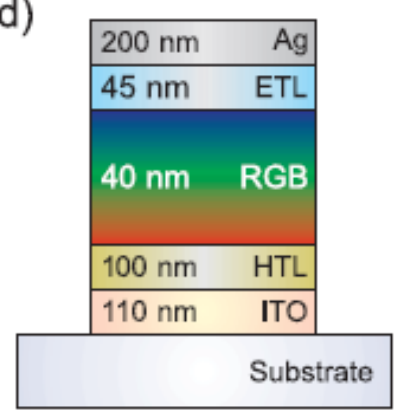

Gambar 14. Berbagai OLED dengan pancaran warna berbeda [5]. (a) Warna biru (b) Warna hijau (c) Warna merah (d) Warna putih menggunakan campuran red-green-blue (RGB) yaitu (red and green phosphorescent, blue fluorescent) sebagai emission layer (EML). 
Lapisan EML yang digunakan untuk menghasilkan warna biru adalah material dengan sifat fluorescence, misalnya Spiro-DPVBi. Untuk menghasilkan warna merah digunakan EML tipe phosphorescence, misalnya platinum octaethylporphyrin (PtOEP). Sedangkan untuk menghasilkan warna hijau digunakan EML tipe phosphorescence, misalnya 4,4'-bis[9-carbazolyl]-2,2'-biphenyl (CBP) yang didope dengan 6,5wt\% tris[2phenylpyridine]iridium ( $\operatorname{Ir}(\mathrm{ppy}) 3)$. Untuk memperoleh warna putih digunakan beberapa cara gabungan red-green-blue (RGB) [6].

\section{Kesimpulan}

Dua tipe OLED, yaitu SMOLED dan PLED memiliki struktur yang berbeda. OLED terbentuk setelah melewati tiga proses utama, yaitu injeksi muatan, pengangkutan muatan, dan emisi cahaya. Berbagai lapisan pada tumpukan material organik dimaksudkan untuk memenuhi tiga proses tersebut, seperti modifikasi pada permukaan Hole Injection Layer (HIL) dan Electron Injection Layer (EIL), pemilihan material yang memiliki mobilitas tinggi untuk pengangkutan seperti Hole Transport Layer (HTL) dan Electron Transport Layer (ETL), demikian juga lapisan emisi dengan pengedop emitter yang memiliki efisiensi tinggi.

Penelitian secara intensif terhadap material Emission Layer menghasilkan OLED dengan kualitas warna yang bagus, efisiensi perangkat, dan kestabilan kerja yang sangat baik. Injeksi dan pengangkutan muatan sangat penting dalam menentukan tegangan kerja dan efisiensi luminans. Warna cahaya yang terbentuk ditentukan oleh pita celah (band gap) material semikonduktor. Digunakan lapisan EML yang berbeda untuk menghasilkan warna yang berbeda.

\section{Daftar Pustaka}

[1] A. Khazanchi, A. Kanwar, L. Saluja, A. Damara, V. Damara, "OLED: A New Display Technology," International Journal Of Engineering And Computer Science," vol. 1, issue 2, h. $75-84,2012$.

[2] A. Singh, H. L. Vishwakarma, "Organic Light Emitting Diodes: Materials, Fabrications and Applications," International Journal of Science and Research," vol. 3, issue 6, h. $577-581$, June 2014.

[3] Y. Karzazi, "Organic Light Emitting Diodes: Devices and Applications," J.Mater. Environ. Sci., vol. 5, no.1, h. $1-12,2014$.

[4] S. Rankel, “OLEDs Organic Light Emitting Diodes," Seminar, University of Ljubljana, Ljubljana, May 2004.

[5] T.D. Schmidt, "Photophysics of organic light-emitting diodes - Device efficiency and degradation processes," Disertasi, Augsburg University, April 2013.

[6] H.T. Nicolai, "Devices physics of white polymer light-emitting diodes," PhD Thesis, University of Groningen, 2012. 
